\title{
Approach to Ferromagnetic Saturation for the Bulk Amorphous Alloy: $\left(\mathrm{Fe}_{0.61} \mathrm{Co}_{0.10} \mathrm{Zr}_{0.025} \mathrm{Hf}_{0.025} \mathrm{Ti}_{0.02} \mathrm{~W}_{0.02} \mathrm{~B}_{0.20}\right)_{97} \mathrm{Y}_{3}$
}

\author{
K. BŁOCH* AND M. NABIAŁEK \\ Częstochowa University of Technology, Faculty of Materials Processing Technology and Applied Physics, \\ Częstochowa, Poland
}

The aim of this paper was to conduct studies concerning the magnetization of bulk amorphous $\left(\mathrm{Fe}_{0.61} \mathrm{Co}_{0.10} \mathrm{Zr}_{0.025} \mathrm{Hf}_{0.025} \mathrm{Ti}_{0.02} \mathrm{~W}_{0.02} \mathrm{~B}_{0.20}\right)_{97} \mathrm{Y}_{3}$ alloy when subjected to strong magnetic fields: the specific focus of the paper is the area known as the approach to ferromagnetic saturation. The investigated alloy samples were produced using the suction-casting method, resulting in plates of dimensions $10 \mathrm{~mm} \times 5 \mathrm{~mm} \times 0.5 \mathrm{~mm}$ and rods of length $20 \mathrm{~mm}$ and diameter $1 \mathrm{~mm}$. The structure was studied using X-ray diffractometry. It was found that investigated samples were amorphous in the as-cast state. The magnetization was measured in a strong magnetic field using a vibrating sample magnetometer. On the basis of the obtained results, the type of structural defects having influence on magnetization in high magnetic fields were determined for the bulk metallic glasses manufactured with different cooling rates.

DOI: $10.12693 /$ APhysPolA.127.413

PACS: 75.50.-y, 75.50.Kj, 75.30.Ds, 75.20.En, 75.47.Np, 75.50.Bb, 75.60.Ej

\section{Introduction}

The bulk amorphous alloys are also called volumetric multicomponent materials. These alloys are characterized by a strong proclivity towards forming an amorphous state, which is achieved by selection of the appropriate chemical composition. The alloy should contain a minimum of three components; the atomic radii of the main components should differ by about $12 \%$, and moreover, the alloy should be characterized by a large negative heat of mixing. It is known that in amorphous alloys there is no long-range ordering of atoms. However, there may be long-range order of the spin magnetic moments in amorphous alloys. The magnetic properties of transition metal alloys explicitly depend on the chemical composition thereof [1-3].

When the sample alloy is subjected to strong magnetic fields, and the domain structure does not exist anymore, a magnetization distribution related to short-range stresses is present. The sources of these stresses can be point defects or quasi-dislocational dipoles [4,5]. One of the indirect methods for investigating the microstructure of ferromagnetic materials is the law of approach to ferromagnetic saturation in magnetization curves. These measurements provide information about the defect structure. As the point of ferromagnetic saturation is approached, there is rotation of the magnetic moments in the vicinity of these defects. Thermally excited spin waves also have an impact on the process of magnetization in strong magnetic fields. High-field magnetization

* corresponding author; e-mail: 23kasia1@wp.pl can be described by the empirical law of the approach to saturation [6]:

$$
\mu_{0} M(H)=\mu_{0} M_{\mathrm{s}}\left(1-\sum_{n=1}^{4} a_{n / 2} / \mu_{0} H^{n / 2}\right)+b\left(\mu_{0} H\right)^{1 / 2},
$$

where $M_{\mathrm{s}}$ - spontaneous magnetization, $\mu_{0}$ - magnetic permeability of a vacuum, $H-$ magnetic field, $a_{1 / 2}, a_{1}$, $a_{2}$ - gradient coefficients of the linear fit related with the type of defect, $b$ - gradient coefficient of the linear fit related to thermal dumping of the spin-waves by the strong magnetic field.

This template can be used for estimation of the length of the published manuscript.

\section{Experimental procedure}

The materials used in the investigations were made using the suction-casting method. The structure of the samples was studied by X-ray diffractometry. The magnetization under the influence of strong magnetic fields was measured using a magnetometer with vibrating sample. The investigations of the structure and magnetic properties were performed on samples which had been powdered in a low energy process.

\section{Results and discussion}

The X-ray diffraction (XRD) curves for the investigated alloy are presented in Fig. 1; they display only one broad maximum, as is characteristic of amorphous materials.

Figure 2 shows high-field magnetization curves, as a function of the magnetizing field, for the investigated alloy. In Fig. 2a, the dependence of the reduced magnetization $\left(M / M_{\mathrm{S}}\right)$ on the magnetic field induction is shown 


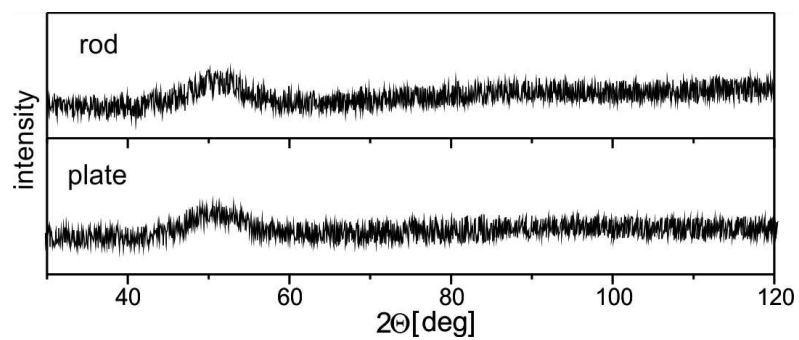

Fig. 1. X-ray diffraction patterns for as-quenched $\left(\mathrm{Fe}_{0.61} \mathrm{Co}_{0.10} \mathrm{Zr}_{0.025} \mathrm{Hf}_{0.025} \mathrm{Ti}_{0.02} \mathrm{~W}_{0.02} \mathrm{~B}_{0.20}\right)_{97} \mathrm{Y}_{3}$ powder.

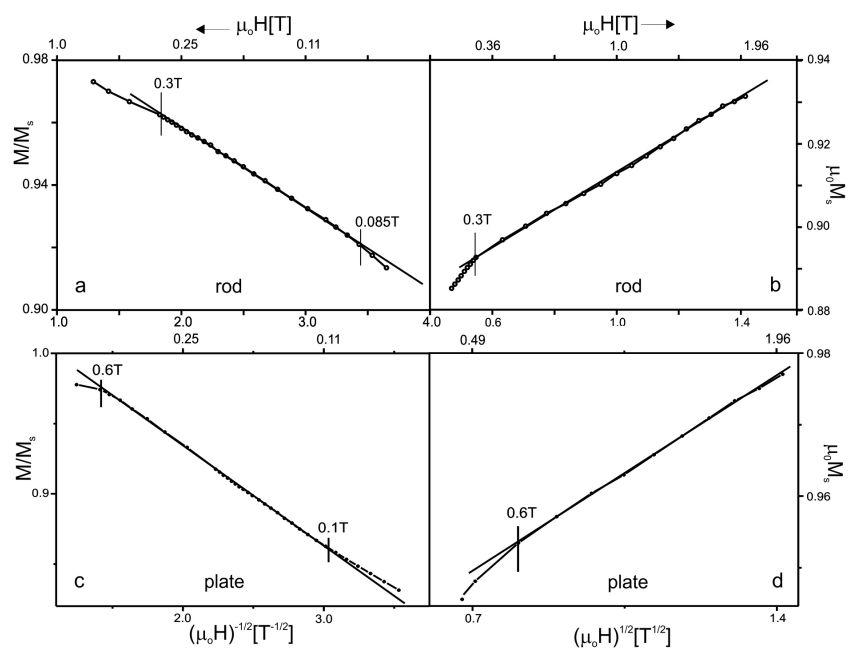

Fig. 2. The high-field magnetization curves $M / M_{\mathrm{s}}\left(\left(1 / \mu_{0} H\right)^{-1 / 2}\right) \quad(\mathrm{a}, \mathrm{c})$ and $M_{\mathrm{s}}\left(\left(\mu_{0} H\right)\right)^{1 / 2} \quad(\mathrm{~b}, \mathrm{~d})$ for the bulk amorphous alloy samples of $\left.\mathrm{Fe}_{0.61} \mathrm{Co}_{0.10} \mathrm{Zr}_{0.025} \mathrm{Hf}_{0.025} \mathrm{Ti}_{0.02} \mathrm{~W}_{0.02} \mathrm{~B}_{0.20}\right)_{97} \mathrm{Y}_{3}$.

for the plate-shaped samples of the alloy. In the magnetic field induction range of $0.1 \mathrm{~T}$ to $0.6 \mathrm{~T}$ a linear dependence of the reduced magnetization on $\mu_{0} H^{-1 / 2}$ has been observed (Fig. 2c). This means that, within this magnetic field range, the magnetization process is connected with small rotations of the magnetic moments in the vicinity of point defects.

In stronger magnetic fields, of more than $0.6 \mathrm{~T}$, a linear dependence of $M_{\mathrm{s}}$ on $\mu_{0} H^{1 / 2}$ has been observed (Fig. 2d). This means that the magnetization process is connected with dumping of the thermally-induced spin waves, and hence is denoted Holstein-Primakoff [7]. Similar shapes of dependence of the reduced magnetization on $\mu_{0} H^{-1 / 2}$ and magnetization on $\mu_{0} H^{1 / 2}$ have been observed for the rod-shaped sample, which, as in the case of the plateshaped sample, is connected to the rotations of the magnetization vectors in the vicinity of the point defects ( $M_{\mathrm{s}}$ proportional to $\mu_{0} H^{-1 / 2}$ ) and with the dumping of the thermally-induced spin waves by the magnetic field (the Holstein-Primakoff paraprocess) (Fig. 2a,b). The data obtained from the analysis of the high-field magnetization curves are presented in Table.
TABLE

Experimental values of the $a_{1 / 2}, b$ parameters and the spin wave stiffness parameter $D_{\mathrm{sp}}$.

\begin{tabular}{|c|c|c|c|}
\hline Parameter & \multirow{2}{*}{$\begin{array}{c}a_{1 / 2} \\
{\left[T^{1 / 2}\right]}\end{array}$} & \multirow{2}{*}{$\begin{array}{c}b \\
{\left[T^{1 / 2}\right]}\end{array}$} & \multirow{2}{*}{$\begin{array}{c}D_{\mathrm{sp}} \\
{\left[10^{-2} \mathrm{eV} \mathrm{nm}{ }^{2}\right]}\end{array}$} \\
\hline $\begin{array}{c}\text { Form } \\
\text { of samples }\end{array}$ & & & \\
\hline plate & 0.0684 & 0.0365 & 60.40 \\
\hline rod & 0.0256 & 0.0451 & 52.45 \\
\hline
\end{tabular}

\section{Conclusions}

The suction-casting method facilitates the production of amorphous alloy samples in the forms of rods and plates. The Kronmüller approach to the ferromagnetic saturation theorem allows for indirect investigations into the structure of the amorphous materials. The results of the investigations in this paper showed that the magnetization process of the alloy is influenced only by point defects and thermally-induced spin waves. This could be explained by the insignificantly small influence of the magnetic anisotropy induced during the production process [8]. The Holstein-Primakoff paraprocess for the rodshaped sample occurs over a much wider range than for the plate-shaped sample. According to [9], in the amorphous materials the mean value of the exchange integral varies over a wide range, and areas exist which feature low values of exchange energy. In these areas, the induction of spin waves of low energy is preferred. This leads to an effective reduction in the $D_{\mathrm{sp}}$ value in comparison to homogeneous materials with the same value of exchange integral. Therefore for the rod-shaped sample a lower value of the spin wave stiffness parameter has been observed.

\section{References}

[1] K. Sobczyk, J. Zbroszczyk, M. Nabiałek, J. Olszewski, P. Brągiel, J. Świerczek, W. Ciurzyńska, A. Łukiewska, M. Lubas, M. Szota, Arch. Metal. Mater. 53, 855 (2008).

[2] A. Inoue, A. Makino, T. Mizushima, J. Magn. Magn. Mater. 215, 246 (2000).

[3] J. Gondro, J. Świerczek, J. Olszewski, J. Zbroszczyk, K. Sobczyk, W.H. Ciurzynska, J. Rzącki, M. Nabiałek, J. Magn. Magn. Mater. 324, 1360 (2012).

[4] H. Kronmüller, J. Ulner, J. Magn. Magn. Mater. 6, 52 (1977).

[5] M.G. Nabialek, P. Pietrusiewicz, M.J. Dospial, M. Szota, K. Błoch, K. Gruszka, K. Oźga, S. Garus, J. Alloys Comp. 615, S51 (2014).

[6] H. Kronmüller, J. Appl. Phys. 52, 1859 (1981).

[7] T. Holstein, H. Primakoff, Phys. Rev. 58, 1098 (1940).

[8] N. Lenge, H. Kronmüller, Phys. Status Solidi A 95, 621 (1986). 